Gut, 1972, 13, 43-46

\title{
Local 'Shwartzman equivalent' reaction in active chronic hepatitis
}

\author{
MICHAEL J. WHELTON \\ From the Department of Medicine, Royal Free Hospital, London
}

SUMMARY The development of a purpura-fulminans-like disorder which is a human equivalent of a local Shwartzman reaction in a woman with active chronic hepatitis is described. The cyclical appearance of blue-black, well circumscribed, haemorrhagic, acutely painful lesions in the buttocks, over the lateral aspects of the thighs, and on the arms suggested the diagnosis. Evidence of increased intravascular coagulation was obtained although interpretation of clotting factor deficiencies in the presence of parenchymal liver disease was difficult. Treatment with heparin arrested the disorder on three separate occasions. The reasons for the development of the syndrome are not clear and even more surprising was the occurrence of such a disorder in the presence of increased fibrinolysis. While disseminated intravascular coagulation has been described in association with liver disease, the development of features of purpura fulminans in such patients does not appear to have been noted.

The Shwartzman reaction is an experimental animal entity which may be local or general. The local Shwartzman reaction is confined to a prepared tissue site, usually the skin. Local injection of a 'preparing' agent (classically Gram-negative endotoxin) followed 24 hours later by intravenous injection of a 'provoking' agent leads to intravascular coagulation with haemorrhagic necrosis of the prepared site. In the generalized Shwartzman reaction two intravenous injections of Gramnegative endotoxin 24 hours apart lead to intravascular coagulation with resultant fibrin thrombi and renal cortical necrosis (Hjort and Rapaport, 1965). Human disorders resembling Shwartzman reactions in animals have been termed 'Shwartzman equivalent' states (Colman and Rodríguez-Erdman, 1970). A patient with active chronic hepatitis who developed a clinical syndrome with features of a local Shwartzman reaction which was reversed by heparin therapy is described.

\section{Case History}

In June 1966 this 21-year-old Caucasian woman was first seen at the Royal Free Hospital where a diagnosis of active chronic hepatitis was made. At the age of 16 years she had been found to have a macrocytic

Present address: Gastrointestinal Unit, St Finbarr's Hospital, Douglas Road, Cork.

Received for publication 13 October 1971. anaemia (haemoglobin $11 \mathrm{~g}$; MCV $125 \mathrm{cmm}$; MCHC $31 \%$ ) and had been treated with vitamin $B_{12}$, folic acid, and iron. Thrombocytopenia (platelets $80,000 / \mathrm{cmm}$ ), primary amenorrhoea, and hepatosplenomegaly were also present at that time and had persisted over the ensuing five years. On 17 July 1966 she was admitted, as an emergency, to hospital with a one-week history of ankle oedema and painful, tender swellings in both buttocks and the anterior abdominal wall. There was no history of recent trauma, infection, or contact with any infectious disease. Haematoma formation was evident in the buttocks and anterior abdominal wall, the spleen was palpable, and there was striae formation, finger clubbing, and leuconychia. Following admission she developed congestive cardiac failure after a period of oliguria. A large, superficial haematoma appeared on the left thigh.

\section{INVESTIGATIONS}

Haematological

Haemoglobin $10.6 \mathrm{~g} / 100 \mathrm{ml}$; reticulocytes $2.6 \%$; platelets $44,000 / \mathrm{cmm}$; white cell count $7,300 / \mathrm{cmm}$; sedimentation rate $9 \mathrm{~mm}$ in the first hour; bone marrow showed megakaryocytes but no platelet budding.

\section{Non-haematological}

Serum total bilirubin $1.2 \mathrm{mg} / 100 \mathrm{ml}$; conjugated $0.8 \mathrm{mg} / 100 \mathrm{ml}$; alkaline phosphatase $15 \mathrm{~K} . \mathrm{A}$. units; total proteins $4 \cdot 1 \mathrm{~g} / 100 \mathrm{ml}$ (albumin $2 \cdot 1 \mathrm{~g} / 100 \mathrm{ml}$ ); 
serum cholesterol $115 \mathrm{mg} / 100 \mathrm{ml}$. A hepatic scintiscan showed a small liver with much uptake in the spleen, features consistent with a diagnosis of hepatic cirrhosis.

\section{PROGRESS REPORT}

Five days after admission the patient's condition became critical with widespread painful haematomas forming over the arms, legs, and trunk (see Figure). She was given a platelet infusion (concentrate prepared from four donors); hydrocortisone $100 \mathrm{mg}$ intravenously and started on prednisolone $60 \mathrm{mg}$ daily. Her condition worsened and she developed hepatic precoma requiring treatment with protein restriction and neomycin. Results of coagulation studies carried out during the sixth and seventh days are summarized in the Table. There wasalso some evidence for fibrinolysis as shown by the plasminogen

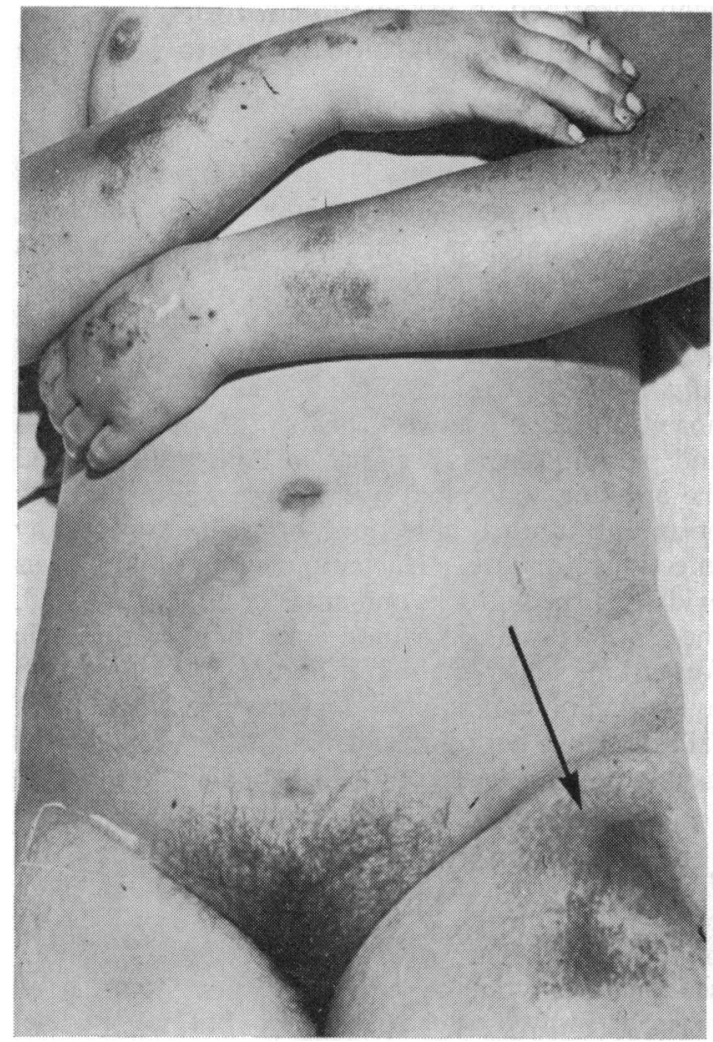

Fig. This illustrates the widespread purpuric lesions, which appeared at the height of the illness. The distribution of the lesions over the lateral surfaces of the thighs and on the backs of the hands is characteristic. Local tissue destruction occurred in the upper left thigh underlying one of the affected areas (arrowed).

\begin{tabular}{|c|c|c|c|}
\hline \multirow[t]{2}{*}{ Test } & \multicolumn{2}{|l|}{ Patient } & \multirow{2}{*}{$\frac{\text { Laboratory }}{\text { Normal Con }}$} \\
\hline & When Bleeding & After Recovery & \\
\hline $\begin{array}{l}\text { Prothrombin time in } \\
\text { seconds } \\
\text { Thrombin time in }\end{array}$ & $21-35$ & $17-20$ & $12-14$ \\
\hline $\begin{array}{l}\text { seconds } \\
\text { Platelets per cmm }\end{array}$ & $\begin{array}{l}18-47 \\
7,000-17,000\end{array}$ & $\begin{array}{l}12-16 \\
30,000-60,000\end{array}$ & $\begin{array}{c}6-11 \\
200,000 \\
500,000\end{array}$ \\
\hline $\begin{array}{l}\text { Factor VIII (\%) } \\
\text { Factor V }(\%) \\
\text { Factor II }\end{array}$ & $\begin{array}{l}60-68 \\
42-50\end{array}$ & $\begin{array}{l}60-105 \\
60-75\end{array}$ & $\begin{array}{l}50-200 \\
50-150\end{array}$ \\
\hline $\begin{array}{l}\text { (prothrombin \%) } \\
\text { Fibrinogen } \\
(\mathrm{mg} / 100 \mathrm{ml})\end{array}$ & $18-42$ & $54-80$ & $50-150$ \\
\hline
\end{tabular}

Table Range of haematological indices during the initial episode of intravenous coagulation compared with the patient's 'normal' range and that of laboratory control levels

level of 1.4 Sherry-casein units (control 5 Sherrycasein units); the presence of fibrin breakdown products to a titre of $1: 16$ and a fibrinolysis titre showing lysis at six hours, to a titre of $1: 8$ (control $1: 64)$. This was not corrected in vitro by the addition of epsilon amino caproic acid.

A diagnosis of disseminated intravascular coagulation with features of the Shwartzman reaction was made. The patient was started on continuous intravenous heparin at an initial dose of 18,000 units followed by 3,000 units hourly. Additional therapy consisted of fibrinogen $5 \mathrm{~g} ; 2$ units of packed red cells; ampicillin $250 \mathrm{mg}$ six hourly; and prednisolone was continued at $\mathbf{4 0} \mathrm{mg}$ daily. Haemorrhagic lesions present ceased to enlarge and new lesions, which continued to appear over the next 48 hours, did not progress in size. All faded rapidly. The patient's general condition gradually improved. On the seventh day of heparin therapy she had a small haematemesis and the heparin was discontinued. No further haemorrhagic lesions occurred and she returned to her pre-bleeding state uneventfully. Tissue loss was restricted to an area over the left thigh in the region illustrated in the Figure. Two further similar episodes occurred in January and July 1967. In both instances heparin therapy was promptly instituted and the patient made a rapid recovery. On one of these occasions cephaloridin was given since the episode was preceded by a mild upper respiratory tract infection. She died in hepatic failure with no evidence of bleeding diathesis after 18 months of follow up. Necropsy was refused.

\section{Discussion}

Disseminated intravascularcoagulation is increasingly being recognized as an underlying bleeding state which occurs in a wide variety of clinical situations. 
The term describes any condition in which depletion of clotting factors I, II. V, VIII, and platelets occurs, with or without compensatory fibrinolysis and regardless of the mechanism by which the clotting system has been activated (Colman and RodríguezErdman, 1970). Likewise a considerable number of human 'Shwartzman equivalent' states have been described (Ackerman, 1942; McKay, Merrill, Weiner, Hertig, and Reid, 1953; McKay, Jewett, and Reid, 1959; Hardaway, Husni, Geever, Hjort and Rapaport, 1965; Moncrieff and Glasgow, 1970). Disease states resembling both a general and local Shwartzman reaction may occur and in the human, unlike the rabbit, distinction is often difficult. The present patient had many features characteristic of purpura fulminans, a human equivalent of a local Shwartzman reaction. Purpura fulminans usually occurs in children one to four weeks after an infectious preparatory disease (Hjort, Rapaport, and Jorgensen, 1964; Antley and McMillan, 1967) associated with leucocytosis, thrombocytopenia, and evidence of intravascular coagulation.

Several days elapsed before the diagnosis of disseminated intravascular coagulation was made in this patient. Initially, it was thought that the bleeding tendency was a manifestation of thrombocytopenia and parenchymal liver disease. The bone marrow result raised the possibility of idiopathic thrombocytopenic purpura but hypersplenism and systemic lupus erythematosus were also considered. Treatment with platelet concentrates and corticosteroids on the fifth day after admission failed to produce a favourable response and, indeed, her condition worsened. The presence of a circulating anticoagulant of the heparin type was suspected but disproved.

The skin lesions were typical of purpura fulminans. The lesions were dark blue, well circumscribed, and appeared in a cyclical fashion. They were extremely painful and in some instances underwent necrosis with subsequent tissue damage. Clotting factors were in keeping with a state of intravascular consumption coagulopathy although interpretation was difficult due to underlying liver disease which of itself may lower vitamin K-dependent factors, namely, factors II, VII, IX, and X in addition to factor $V$ and platelets.

During her 'normal' periods, between episodes of intravascular coagulation, she had intermittently low levels of factor II, V, and fibrinogen but normal levels of factor VIII (Table I). Her platelet count had been low for five years. During her attacks, factors II and V fell further as did fibrinogen and platelets, whilst factor VIII fell but remained within normal limits (Table I). Improvement in the levels of all these factors followed recovery from each episode of intravascular coagulation. Recovery seemed to occur only after the introduction of heparin therapy although the administration of antibiotics concomitantly may have played some part. Corticosteroid therapy alone appeared to have no beneficial effect and indeed the patient's condition worsened following the introduction of this treatment. It is of interest that on the third occasion we treated this patient she had an actual rise of factor VIII to $150 \%$ before treatment, the level reverting to normal after heparin therapy. A similar finding has been reported by Zetterqvist and Von Franken (1963).

The occurrence of disseminated intravascular coagulation in patients with liver disease has been reported by several authors (Zetterqvist and Von Franken, 1963; Johansson, 1964; Rake, Flute, Pannell, and Williams, 1970). Manifestations of a local Shwartzman reaction do not appear to have occurred in these patients. The presence of consumption coagulopathy alone, however, is insufficient for the development of the Shwartzman reaction, other modifying factors, particularly defective fibrinolysis, being necessary (Colman and Rodriguez-Erdman, 1970). The pathogenesis underlying the acute illness in the present patient is unknown as is the role of her liver disease. Increased, rather than decreased, fibrinolytic activity has been described in many forms of liver disease (Von Kaulla, 1963) though it is poorly correlated with clinical bleeding disorders in such patients. The present patient also had some evidence of increased fibrinolysis. Although a mild infection did precede one episode, there was no other evidence to suggest endotoxic shock nor was she gravid during any of her attacks.

The clinical features, course, and response to heparin were fully consistent with a diagnosis of purpura fulminans, a human equivalent of a local Shwartzman reaction. Heparin therapy prevents the experimental Shwartzman reaction (Good and Thomas, 1953) and there is good evidence of its value in human equivalent states (Hjort and Rapaport, 1965). Corticosteroids potentiate the Shwartzman reaction and, while they may be necessary to combat shock, should probably only be administered in addition to heparin where this syndrome is suspected

The difficulty of diagnosis in patients with cirrhosis who develop a bleeding diathesis has been mentioned and in this patient the diagnosis was not made for several days. The possibility of disseminated intravascular coagulation should be considered in patients with both acute and chronic liver disease who develop a bleeding diathesis with unusual features. Therapy with heparin in an established case, is logical, and, as in this patient, may be life 
saving. It should be undertaken, however, with circumspection.

My thanks are due to Professor S. Sherlock for permission to publish details of this case. I wish to thank Dr Enid Bennett, University College Hospital, who carried out most of the haematological investigations and helped in the preparation of the manuscript. Dr A. A. Sharp (Oxford) gave much valuable advice in the management of this patient in addition to measuring fibrin degradation products. Dr P. T. Flute, King's College Hospital, kindly did the plasminogen assays.

\section{References}

Ackerman, L. V. (1942). Acute pancreatitis following blood transfusion. Arch. Path., 34, 1065-1069.

Antley, R. M., and McMillan, C. W. (1967). Sequential coagulation studies in purpura fulminans. New Engl. J. Med., 276, 12871290.

Colman, R. W., and Rodriguez-Erdman, F. (1970). Terminology of intravascular coagulation. New Engl. J. Med., 282, 99.

Good, R. A., and Thomas, L. (1953). Studies on the generalised Shwartzman Reaction. IV. Prevention of the local and generalised Shwartzman reactions with heparin. J. exp. Med., 97, 871-888.

Hardaway, R. M., Husni, E. A., Geever, E. F., Noyes, H. E., and
Burns, J. W. (1961). Studies on the relationship of bacterial toxins and intravascular coagulation of pseudomembranous enterocolitis. J. surg. Res., 1, 121-127.

Hjort, P. F., and Rapaport, S. I. (1965). The Shwartzman reaction: pathogenetic mechanisms and clinical manifestations. Ann. Rev. Med., 16, 135-168.

Hjort, P. F., Rapaport, S. I., and Jorgensen, L. (1964), Purpura fulminans: report of a case successfully treated with heparin and hydrocortisone-review of $\mathbf{5 0}$ cases from the literature. Scand. J. Haemat., 1, 169-192.

Von Kaulla, K. N. (1963). Chemistry of Thrombolysis: Human Fibrinolytic Enzymes. Thomas, Springfield, III.

Johansson, S. A. (1964). Studies on blood coagulation factors in a case of liver cirrhosis. Remission of haemorrhagic tendency on treatment with heparin. Acta med. scand., 175, 177-183.

Moncrieff, M. W., and Glasgow, E. F. (1970). Haemolytic-uraemic syndrome treated with heparin. Brit. med. J., 3, 188-191.

McKay, D. G., Jewett, J. F., and Reid, D. E. (1959). Endotoxin shock and the generalised Shwartzman reaction in pregnancy. Amer. J. Obstet. Gynec., 78, 546-566.

McKay, D. G., Merrill, S. J., Weiner, A. E., Hertig, A. T., and Reid, D. E. (1953). The pathologic anatomy of eclampsia, bilateral renal cortical necrosis, pituitary necrosis and other acute fatal complications of pregnancy, and its possible relationship to the generalized Shwartzman phenomenon. Amer. J. Obstet. Gynec., 66, 507-539.

Rake, M. O., Flute, P. T., Pannell, G., and Williams, R. (1970). Intravascular coagulation in acute hepatic necrosis. Lancet, 1 , 533-537.

Zetterqvist, E., and Francken, I. Von (1963). Coagulation disturbances with manifest bleeding in extrahepatic portal hypertension and in liver cirrhosis. Preliminary results of heparin treatment. Acta med. scand., 173, 753-760. 